\title{
Leprosy in Korea with Special Reference to the Soonchun Leprosy Colony.
}

\author{
R. M. WILSON.
}

W HILE there is nothing startling to report yet we are greatly encouraged with the results of treatment and believe that with faith, determination and persistence, most cases in the early stages of the disease will respond to treatment satisfactorily. We have found nothing so good, simple and economical as plain chaulmoogra oil with camphor, 4 to 6 ccs. given subcutaneously twice a week. While this is the chief drug, there are other things of importance, viz., exercise and out-door employment. We find that vegetable gardening is one of the best activities for patients, as there are very few who cannot take some part, even the blind, and it gives out-door exercise, diversion, interest and, what is very important from an economic standpoint, it reduces the expenditure on vegetables. The raising of white rabbits is also a useful occupation and provides the cheapest source of meat. There are several thousand in the colony.

Ultra violet rays are proving of benefit in the treatment, so we take advantage of the sun's rays. Our patients wear short sleeves, take off their shirts while at work, and start the exposure early in the spring. Other activities are tennis and football for the pupils in school, carpentry, tin and blacksmith shops and various forms of home industries. The busier the patients are the better. However, it is not easy to persuade 750 Koreans to work when there is a good, hot floor near by. In the past, sufferers in certain places made long and strenuous trips to temples and high places to appease the spirits and after a few months were found to have improved. The real benefit from such a journey was from the exercise and activity. Exercise and life in the open is a most important aid in treatment.

Another very important point which has been stressed by others is that complicating disease should be given prompt treatment. Chief among these is syphilis, tuberculosis, nephritis and hookworm. We give each syphilitic case $\frac{1}{2} \mathrm{gr}$. salyc. mercury dissolved in the chaulmoogra oil and in this way combine the injections. Care of the teeth and extractions of carious ones are important.

Finding the acid fast bacilli in the sputum of leprosy patients does not mean that they are necessarily tubercular, 
for frequently the mycobacterium lepræ will be found in the sputum as a result of ulceration of the respiratory tract. Before making a diagnosis one should consider the pulse, temperature and physical signs. We have isolated such cases on this evidence alone, only to see them increase in weight and improve rapidly on suitable diet.

Among our 750 cases, 21 of them are blind, and 92 (12 per cent.) have some eye complication or weakness. Our patients feel sure that the esters were injurious to the eyes, but I cannot agree with this. One hundred and thirteen of the patients received chaulmoogra by mouth and six hundred and seven by injection. They are excused from injection only if some complication arises or for some other good reason. Treatment by injection is, of course, the best and most economical method. Unless taken in large doses, the oral route is not as effective as injections. During the year, we had 30 abscesses and that is 30 too many. We now boil the needles in linseed oil which is an improvement. Twenty cases had lepra reaction or fever. Often patients will pick up and make rapid improvement after such reactions, though, occasionally, there is retrogression. Four hundred and fifty of our cases are leading an active life and 270 are, more or less, helpless owing to their infirmities We obtain our oil in 50-gallon tanks from Bangkok, Siam. The tank is placed on a charcoal fire to melt the oil, filtered through a few layers of gauze and drawn off into pound bottles which are put into an autoclave or water bath, when the 5 grams of camphor are added. Iodine is applied before and after each injection.

In the Philippines, where 2,818 injections of the esters were given, 70 per cent. made complaints of pain, dizziness, fever, headache, cough, etc. It is almost impossible to persuade our patients to take the esters. Recently the Government gave a supply of the esters to a beggar settlement situated near us and they refused to take the esters, even though in doing so they would have no treatment at all. However, some of the big institutions continue to use the esters with good results.

On a recent trip to Tokyo, I visited the Zensei Byo-in settlement, 20 miles from the heart of the city, where 1,000 cases are housed in one of the best institutions I have seen. They have a staff of six doctors, under the very able leprologist, Dr. Mitsuda. They carry on many splendid activities and are doing a high grade of work. Practically every form of leprosy tissue is demonstrated in both gross and microscopic form, also wax figures showing all shades 
and conditions of the disease. The patients have gardens and shops and print a paper, and in every way it is an active and wideawake place. There are 15 Koreans among those cases who are fortunate enough to be in such a fine institution.

During our meeting in Tokyo, the Government officials reported their plans for the eradication of leprosy from the empire in the next 30 years. Much enthusiasm is being aroused, and I feel that there is a brighter day ahead for those suffering from leprosy. I believe far more rapid progress will be made if sufferers from leprosy were under strictly medical men rather than the police, who of ten do not understand the situation and are very fearful of contact with the disease. There is such a fear that it is almost impossible to help clinics or give patients treatment outside of the four leprosy institutions. Splendid work is being done in the Philippines and in India by doctors at outpatient clinics and hospitals, and any who can do so are encouraged to give treatment to those suffering from the disease. In this country, however, in practically every town and village, the doctors are so fearful of attracting a few cases to their dispensaries that treatment cannot be obtained. Consequently, hundreds of cases of leprosy travel from one place to another seeking care and relief, only to be driven away. I have tried in several places to start clinics, but have been unsuccessful on account of the fear of attracting cases to the district.

In Bihar, India, last year, 5,923 cases were treated in outpatient clinics at a very small cost and with good results. In India, many of the doctors are given a special course of training concerning the disease and this encourages them to treat the cases which come to them. Only a little over 2,000 of the probably 20,000 sufferers in Korea are receiving treatment, and many of these are blind, non-infectious arrested cases beyond hope of a cure. The other 18,000 cases, however, in the earlier stages of the disease, are unattended and are spreading the infection.

As the Japanese Government has shown itself in the past to be efficient and active in dealing with sanitary questions, no doubt the problem of leprosy will be taken in hand and dealt with efficiently in the near future. 